\title{
BAIXO RENDIMENTO ESCOLAR E PROGRESSÃO CONTINUADA: CONCEPÇÕES DE ALUNOS, PROFESSORES E RESPONSÁVEIS.
}

Keila Hellen Barbato MARCONDES ${ }^{1}$

Silvia Regina Ricco Lucato SIGOLO ${ }^{2}$

RESUMO: Este trabalho objetiva analisar as concepções de professoras, crianças e adultos responsáveis por crianças sobre as temáticas de rendimento escolar e Progressão Continuada. O referencial teórico adotado é a perspectiva bioecológica de Bronfenbrenner. O estudo ocorre em uma cidade do interior de São Paulo/ Brasil, tendo como sujeitos seis famílias e seis crianças - que estavam no final do ciclo I do Ensino Fundamental e que apresentavam um baixo rendimento escolar - e suas respectivas professoras. A coleta de dados foi realizada por meio de entrevistas e observações do cotidiano escolar. As análises indicam que professoras, alunos e responsáveis sofrem com o baixo rendimento da criança, apesar de demonstrarem diferentes concepções e ações frente a essa realidade. Quanto à progressão continuada, podese afirmar que as docentes discordam de tal política, afirmando que foi implantada autoritariamente. Por outro lado, pode-se constatar que adultos responsáveis e crianças não possuem informações sobre a progressão continuada e apontam como negativa a promoção automática que vem ocorrendo no processo de escolarização. Cabe destacar que é evidente a divergência de informações entre as instâncias familiares e escolares, o que indica a necessidade de refletir sobre essa interconexão e buscar novas formas de relações.

PALAVRAS-CHAVE: Baixo rendimento escolar. Progressão continuada. Ensino fundamental.

\section{Introdução}

O Regime de Progressão Continuada especificamente adotado no Estado de São Paulo/ Brasil, foi implementado a partir de 1998, tendo como base a LDB 9394/96 (BRASIL, 1996). Assim sendo, os professores que iriam lecionar nos ciclos deveriam atuar de forma distinta do sistema seriado até então utilizado, era necessário pensar em uma aprendizagem que fosse contínua, respeitando o ritmo do aluno (SÃO PAULO, 1997a).

A Indicação do Conselho Estadual de Educação (CEE) 8/97 que fundamenta a Deliberação 9/97 apresenta o Regime de Progressão Continuada como “[...] uma estratégia para viabilização da universalização da educação básica, da garantia de acesso e permanência das crianças em idade própria na escola [...] e da melhoria da qualidade do ensino.” (SÃO

\footnotetext{
${ }^{1}$ Doutoranda em Educação Escolar. UNESP - Universidade Estadual Paulista. Faculdade de Ciências e Letras Programa de Pós-Graduação em Educação Escolar. Araraquara - SP - Brasil. 14800-901 keilamarcondes@yahoo.com.br

${ }^{2}$ UNESP - Universidade Estadual Paulista. Faculdade de Ciências e Letras - Departamento de Psicologia da Educação - Programa de Pós-Graduação em Educação Escolar. Araraquara - SP - Brasil. 14800-901 sigolo@fclar.unesp.br
} 
PAULO, 1997b, p.01). Segundo o CEE, a proposta permitiria o fim da evasão escolar, da reprovação autoritária e da exclusão do aluno com relação à sociedade e ao saber. No entanto, algumas pesquisas têm revelado que a Progressão Continuada tem contribuído exatamente de forma contrária, excluindo muitos alunos em relação ao conhecimento e a sociedade. Os professores se queixam que ao final do ano letivo os alunos não haviam aprendido a ler e a escrever (RAVAGNANI, 2001; SILVA, 2001).]

O presente estudo pretende enfocar exatamente o contexto de progressão continuada, buscando analisá-las sob a perspectiva das docentes, crianças e responsáveis. Além do objetivo de compreender a concepção de progressão continuada, visa-se, no trabalho, compreender as concepções de baixo rendimento escolar, à medida que as crianças estudadas apresentam tais condições.

O intuito de compreender a visão de responsáveis, alunos e professores se justifica por conceber que essas questões afetam a todos os que estão envolvidos direta e indiretamente com o sistema escolar, sendo necessário atentar para essas influências e interconexões que se estabelecem. Contudo, a literatura aponta que os estudos centram-se, em sua maioria no professor, o que é imprescindível, contudo, há uma lacuna em relação a outros sujeitos. Desta forma, oportunizar as manifestações de crianças e responsáveis mostra-se extremamente relevante.

Ainda é necessário ressaltar, para uma melhor compreensão do estudo, a concepção de baixo rendimento escolar. De acordo com Carvalho (2000) o objetivo da escolarização é a aquisição de conhecimentos construídos sócio-culturalmente, pensando nas etapas iniciais desse processo os conteúdos seriam as aquisições da leitura, escrita e cálculos elementares. Assim sendo, o baixo rendimento escolar se traduziria como uma resposta inadequada a essa aquisição ou ainda uma apreensão parcial dos conhecimentos esperados para essa fase.

Para atender o objetivo dessa pesquisa, adotou-se a perspectiva bioecológica como embasamento teórico pertinente, possibilitando responder ao problema de pesquisa proposto, na medida em que este referencial permite analisar a complexidade das relações entre família e escola e, entre os dois contextos e as políticas públicas para a educação.

Na teoria bioecológica, “[...] os processos psicológicos passam a ser propriedades de sistemas, nas quais a pessoa é apenas um dos elementos, sendo o foco principal os processos e as interações.” (NARVAZ; KOLLER, 2005, p.52). Sendo assim, a perspectiva enfatiza que tanto o indivíduo que está em desenvolvimento se modifica ao entrar em contato com um meio que lhe ofereça possibilidades, como também este ambiente é modificado através da interação com o indivíduo, ou seja, é um processo bidirecional. 
A perspectiva bioecológica conceberá o desenvolvimento, portanto, como sendo o produtor e o produto dos processos de interação - que devem ser recíprocos - entre o ser humano biopsicologicamente ativo e os múltiplos contextos, sendo necessário que esse desenvolvimento ocorra através do tempo. Destacam-se do contexto, como agentes promotores de desenvolvimento, as pessoas, os objetos e os símbolos.

O contexto vai ser compreendido na perspectiva bioecológica como sendo uma série de estruturas encaixadas, uma dentro da outra, diferenciando-se em quatro níveis: micro-, meso-, exo- e macrossistema. Essas influências ambientais formam um "pano de fundo” para a compreensão dos processos psicológicos, permitindo assim um melhor entendimento deles.

Nesta série de encaixes, o nível mais interno é o chamado microssistema. Este pode ser a casa, a sala de aula, a casa do amigo. Um microssistema é um padrão de atividades, papéis e relações interpessoais experienciados pela pessoa em desenvolvimento num dado ambiente, com características físicas e materiais específicas. Esse contexto apresenta-se como primordial para o desenvolvimento humano, na medida em que nele ocorrem os processos proximais.

O segundo nível é o mesossistema, que inclui as interconexões entre dois ou mais ambientes, nos quais o indivíduo tem participação ativa.

O terceiro nível que faz parte do ambiente ecológico é o exossistema, que é definido como uma interconexão de vínculos entre ambiente imediato, onde o indivíduo participa ativamente, e outros ambientes dos quais não participa diretamente, mas que possuem características que influenciam o seu cotidiano. Um exemplo de influência de exossistema seria o trabalho dos pais. Devido ao emprego, os pais poderão ter um menor tempo de contato com os filhos, tal condição pode resultar em diferentes padrões de interação. Deve-se ressaltar que uma menor quantidade de tempo não significa necessariamente menor qualidade de interação.

O último nível, o mais externo, é o macrossistema, definido como um sistema de idéias, valores, crenças e ideologias subjacentes à forma dos conteúdos do micro, meso e exossistema.

O macrossistema pode ser pensado como uma "radiografia social”, formado pelas características do micro, meso e exossistema como os valores, recursos, riscos, em seu caráter histórico e cultural, que vão sendo assimilados no processo de desenvolvimento e difundidos entre as gerações, por meio de instituições culturais e estruturas governamentais, sendo que, ainda nesta evolução, sofrem modificações advindas dos valores e condutas dos indivíduos em outros níveis do sistema. 
Tendo em vista a importante influência que há entre os diversos sistemas, que se afetam reciprocamente a progressão continuada é indicada como sendo uma das reformas políticas (macrossistema) que têm produzido grande impacto, não somente nos profissionais da educação como também nos alunos e suas famílias (microssistema), principalmente nos casos de alunos com baixo rendimento acadêmico.

\section{Método}

O presente estudo foi desenvolvido em uma escola situada em um bairro periférico da cidade do interior do Estado de São Paulo/Brasil. Foram sujeitos da pesquisa seis crianças que, no ano de 2004, freqüentaram o último ano do ciclo I do ensino fundamental, cujo rendimento escolar foi identificado como baixo, suas respectivas famílias e docentes.

As indicações das crianças foram feitas pelas professoras, que usaram como critério de escolha a baixa aquisição nos conhecimentos de matemática, leitura e escrita prevista para essa etapa de escolarização.

Para a coleta de dados foram utilizadas entrevistas semi-estruturadas, as quais foram elaboradas e previamente testadas para adequação dos objetivos e observação de conselhos de classe.

A coleta de dados com as crianças ocorreu na escola durante oito encontros, onde se pode estabelecer um vínculo de confiança entre sujeito e pesquisadora. As entrevistas com as mães foram realizadas durante os meses de outubro e novembro de 2004 nas residências das próprias famílias. Quanto à coleta com as docentes, essa ocorreu na própria escola, em horários em que as professoras estavam livres.

Após a coleta os dados foram lidos cuidadosamente e categorizados, em seguida, buscou-se as divergências e convergências dos depoimentos dos três grupos de sujeitos (responsáveis, crianças e docentes) e, finalizou-se com a triangulação dos referidos dados.

\section{Resultados}

Os resultados serão apresentados divididos em dois grandes grupos temáticos: baixo rendimento escolar e progressão continuada. Cada grupo temático foi dividido em subcategorias, a saber:

1- Baixo rendimento escolar: concepções que permeia o conceito de baixo rendimento; atitudes da escola frente aos desempenhos; Os sentimentos experienciados; Expectativas 
frente ao baixo rendimento; sugestões para o suporte dos alunos com baixo rendimento escolar e vínculo família-escola.

2- Progressão Continuada: informações e formas de transmissões; Implementações políticas

\section{Baixo rendimento escolar}

As concepções que permeiam o conceito de baixo rendimento escolar são divergentes entre os grupos de sujeitos. As professoras indicam que o baixo desempenho está relacionado às questões relacionadas à família e ao próprio aluno. As mães, contudo, apresentam um leque maior de possibilidades, apontam situações da família, da escola e do próprio filho. As crianças, por sua vez, indicam a si próprios como “culpados” pelas dificuldades de aprender.

As docentes, portanto, continuam a apontar que as condições socioeconômicas, a estrutura familiar e um possível “desinteresse” das crianças pelas atividades escolares são as causas do baixo desempenho. Como afirmam Habigzang et al. (2005, p.371), há uma “[...] reatualização dos mitos que sempre acompanharam o fracasso (mito da carência ou privação cultural, mito da desnutrição, mito do QI, etc).” As possíveis ações educacionais excludentes e discriminatórias não são indicadas.

De acordo com os autores anteriormente citados, tal visão impede que haja a consideração das disposições pessoais geradoras de desenvolvimento do indivíduo, anulandoas frente às "dificuldades de seus recursos e demandas, bem como ao contexto no qual estavam inseridas, impedindo, assim, qualquer crescimento do aluno e minimizando o compromisso da escola com este crescimento".

As atitudes da escola frente aos desempenhos considerados inadequados se caracterizaram pelo encaminhamento ao reforço escolar e à avaliação psicológica ou neurológica. Evidencia-se assim uma visão medicalizante e patologizante da aprendizagem dos alunos. De acordo com Patto (1992), o encaminhamento da escola para especialistas, com o intuito de receber laudos que confirmem diagnósticos de patologias, tem como objetivo legitimar a visão da escola e transferir a responsabilidade do baixo rendimento para a criança e a família.

Os sentimentos experienciados, por todos os sujeitos, diante da situação do rendimento inadequado são os de angústia e tristeza. Entretanto, as expectativas para o desenvolvimento da criança, em sua maioria, eram consideradas positivas. 
Há que se salientar a importância das expectativas para o investimento do aluno em seu potencial. Carvalho (2000) afirma que a maneira pela qual docente e responsável visualizam o aluno pode afetar o seu desempenho em sala de aula. Apresentar perspectivas positivas pode ser apontado como importante recurso para o desenvolvimento infantil.

Pode-se concluir que as expectativas positivas têm um valor incomensurável para os alunos. Apesar das frustrações nas tentativas de aprender e dos sentimentos negativos relacionados aos seus rendimentos, as crianças continuavam a investir na aprendizagem.

As crianças destacaram a figura da professora como sendo de vital importância, sublinhando o relacionamento afetivo que mantinham com as docentes. Tais características, a reciprocidade e o equilíbrio de poder, são ressaltadas por Bronfenbrenner (1996) como imprescindíveis para uma relação diádica efetiva e capazes de gerar desenvolvimento. Os dados permitem afirmar que a maioria das relações entre professora e aluno balizava-se nesse tripé, exceto em um caso.

As sugestões para o suporte dos alunos com baixo rendimento escolar são condizentes com as concepções de sua causa. Docentes indicam a continuidade do reforço e do auxílio da família. As responsáveis, no entanto, apresentam um número considerável de possibilidades de suporte que estão relacionadas à escola, à família e ao próprio filho. Os alunos, no entanto, indicaram a necessidade de haver "apoio de outras pessoas".

Como afirma Lisboa e Koller (2005), é necessário que a criança possua uma rede social e afetiva de suporte, que esteja disponível para auxiliá-la quando há problemas com sua escolarização. As autoras ressaltam a necessidade de pais e professores estarem atentos e agirem em parceria. A necessidade de apoio das figuras docente e parental foi freqüente nos depoimentos das crianças.

O baixo rendimento escolar, portanto, é uma questão que perpassa as relações estabelecidas entre família e escola. Observa-se que a escola ainda aponta as questões extraescolares como "causas" dos desempenhos inadequados, mantendo uma visão estereotipada e negativa sobre as famílias de classe popular. No entanto, a família apresenta uma nova forma de conceber o baixo rendimento, asseverando as relações existentes entre os fatores intra e extra-escolares. O grupo familiar aponta que há a necessidade de haver maior apoio da própria família e empenho do aluno, contudo indica que a escola também precisa repensar suas ações. E, para tal reavaliação, o olhar da família teria muito a contribuir.

Os resultados obtidos pela pesquisa indicam pontos que necessitam ser alvos de reflexão, com o intuito de melhor compreender os contextos estudados e alterar situações que possam não ser favorecedoras do desenvolvimento infantil. 
Quanto às questões de rendimento escolar, os dados refletiram a diversidade de desempenhos que são encobertos por tal nomenclatura. Este resultado indica que há necessidade das docentes ficarem sempre atentas às peculiaridades de cada aluno. É necessário ressaltar que as professoras demonstraram um conhecimento aprofundado quanto ao rendimento atual dos alunos, mas, em alguns casos, não foram capazes de indicar a trajetória de escolarização das crianças, informação imprescindível para o conhecimento mais aprofundado do rendimento destas.

Os resultados indicaram, ainda, que para as docentes terem acesso ao histórico de aprendizagem da criança, seria necessário um maior vínculo do contexto escolar com o familiar. Pode-se afirmar que a família tem muito a contribuir com a escola. Informações como as do histórico, entre outras, podem auxiliar as docentes a repensarem estratégias de ensino-aprendizagem que sejam efetivas especificamente para aquela criança.

O vínculo entre a família e a escola mostra-se, portanto, necessário para que se possa repensar a instituição escolar. As concepções das famílias e dos alunos trazem informações e saberes ignorados pela escola e que poderiam contribuir para se repensar as ações escolares.

\section{Progressão Continuada}

Conforme discutido no início do texto, o regime de progressão continuada constitui-se em uma política educacional implementada no Estado de São Paulo há 10 anos.

Pode-se constatar, com a pesquisa que a escola é seletiva quanto às informações e formas de transmissões que oferecem aos responsáveis no que se referem às políticas educacionais, especificamente a Progressão Continuada. Observar-se um desencontro de informações relacionadas ao regime de progressão continuada.

Algumas mães demonstram em seus relatos a crença de que seus filhos possam ser reprovados nesse momento devido às modificações na legislação, sem saber que era exatamente a mesma lei que previa essa possibilidade no final do ciclo I. Confusões e leituras equivocadas do regime são constatáveis, na medida em que os responsáveis não foram informados pela escola de maneira adequada. Na percepção das professoras, os informes transmitidos foram suficientes para esclarecer às famílias as modificações advindas da implementação da política educacional, contudo, pode-se afirmar, diante dos dados, que não foram suficientes ou eficazes as formas de transmissão adotadas.

As professoras confirmam que os responsáveis receberam as informações quando foram questionar a escola sobre a aprovação dos filhos sem rendimento adequado, para a série 
subseqüente, ou quando foram avisadas da possibilidade da retenção do filho no final do ciclo I.

A falta de informação também é observada nos depoimentos dos alunos, que questionavam algumas ações adotadas pela escola, como a aprovação sem rendimento esperado.

É necessário ressaltar que as políticas educacionais foram implementadas sem discussões prévias com os docentes, desvalorizando-os e desqualificando-os, por serem postas em ação de maneira vertical. Dessa forma, os docentes transmitiram as informações aos pais e alunos de acordo com as informações por elas recebidas (MAGALHÃES, 2004).

A maneira como as implementações políticas foram feitas não auxiliam a compreensão e a aceitação pelos professores, que são obrigados, repentinamente, a mudarem suas ações sem discussões prévias e desconsiderando seus saberes. É possível que, diante da situação, o docente não se mobilize a conhecer aprofundadamente a nova política educacional e resista à mudança, preservando suas concepções e agindo em consonância com elas. Como afirma Guilherme (2003), buscando estratégias para adaptar-se a nova realidade. Se o docente possui informações inconsistentes e genéricas sobre a progressão continuada transmitirão aos pais o que sabem, podendo causar desencontros.

Os dados ainda possibilitam mais uma conclusão, ou seja, apesar das professoras não conhecerem adequadamente as novas políticas educacionais, há diferenças no “como” as transmitem. Os docentes oferecem informações à família na dimensão proporcional ao auxílio de que necessitam da mesma. Se uma quantidade de informação possibilita a transmissão adequada das instruções da escola, essa é a medida ideal de comunicação necessária.

Como os docentes não percebem a necessidade de “envolvimento” dos responsáveis em relação à Progressão, as informações são transmitidas de maneira superficial, pois consideram que eles não possuem competência para compreendê-las e menos ainda condições participativas (MAGALHÃES, 2004), ou seja, voz ativa nas decisões intra-escolares (SILVA, 2001). É importante ressaltar que a docente pode também não dominar muito a legislação como se afirmou anteriormente.

\section{Conclusões}

Os resultados permitem concluir que o termo rendimento acadêmico torna homogêneo um quadro de peculiaridades de aprendizagens dos alunos, por isso, deve-se engendrar esforços para compreender as particularidades de cada criança, atentando para suas 
habilidades, prevendo uma avaliação diagnóstica que possa garantir uma intervenção efetiva, com o intuito de sanar as dificuldades.

A escola salienta que o desempenho inadequado dos alunos tem relações com problemas familiares. No entanto, há que se ressaltar que as famílias, diferentemente das docentes, destacam uma visão mais abrangente e inter-relacionada, indicando a escola, a família e o aluno como possíveis agentes que interferem negativamente no rendimento acadêmico.

A Progressão Continuada constituiu-se como uma forte influência do macrossistema nas relações entre responsáveis e professoras pesquisadas. O desrespeito aos saberes docentes foi o marco dos depoimentos das professoras, que afirmam se sentirem coagidas a adotarem uma política educacional sem qualquer possibilidade de discuti-la. Além disso, algumas docentes apontam discordâncias com o pressuposto da política, que é ignorada pelos legisladores e executada verticalmente. As famílias e os alunos também foram considerados meros expectadores da implementação da Progressão, pois os legisladores não os escutaram e a escola não lhes informou adequadamente.

Pode-se afirmar, portanto, que há desencontros referentes às informações das políticas educacionais e os contextos que por elas são influenciados, apontando uma grande lacuna nas inter-relações da escola com a família, nos levando a uma hipótese de que é necessária uma maior atenção a esse vínculo.

Bronfenbrenner (1996) destaca essa relação como essencial para o aluno, de acordo com o autor para que um ambiente funcione como um contexto de desenvolvimento para o individuo depende da “[...] existência e natureza das interconexões sociais entre os ambientes, incluindo a participação conjunta, a comunicação e a existência de informação em cada ambiente a respeito do outro.” (BRONFENBRENNER, 1996, p.7). Podemos afirmar, perante aos dados, que existe uma falta de interconexão entre esses dois ambientes.

Finalmente, podemos concluir que é de suma importância que se conheçam todos os sujeitos envolvidos com o processo ensino-aprendizagem, suas concepções e percepções, já que essas afetam diretamente o ambiente em que está inserido. 


\title{
A STUDY ABOUT CONCEPTIONS OF CHILDREN, TEACHERS AND THE ADULTS RESPONSIBLE FOR THE CHILDREN ABOUT THE SCHOOL ACHIEVEMENT AND CONTINUED PROGRESSION
}

\begin{abstract}
The aim of this work is to analyze the conceptions of children, teachers and the adults responsible for the children about the school achievement and Continued Progression. The theoretical basis of this work is Bronfenbrenner's bioecological perspective. This study takes place in a city of the interior of São Paulo/ Brazil, and the participants are six families and six children - who were in the end of the cycle I of the Fundamental Teaching with school underachievement - and the teachers of those children. The data collection was accomplished through interviews and observations of the daily school routine. The data analysis indicates that the teachers, students and the adults responsible suffer with the underachievement even demonstrating different conceptions and actions about this reality. Taking into account the Continued Progression, one can say that the teachers don't agree with such policy because its implantation was an authoritarian act. On the other hand, the adults responsible and the students don't owe information about the Continued Progression and the automatic promotion point it as negative during the learning/teaching process. It's necessary to emphasize the evident divergence of information among the family and the school professionals, what indicates the need to think about this interface and to look for new ways of relationship.
\end{abstract}

KEYWORDS: Underachievement. Continued Progression. Fundamental Teaching.

\section{REFERÊNCIAS}

BRASIL. Lei n. 9.394, de 20.12.1996. Estabelece Diretrizes e Bases da Educação Nacional.

Diário Oficial da União, Brasília, n.248, ano 134, p.27.833-27.841, 1996.

BROFENBRENNER, U. A ecologia do desenvolvimento humano: experimentos naturais e planejamentos. Tradução de Maria Adriana Verissimo Veronese. Porto Alegre: Artes Médicas, 1996.

CARVALHO, A. M. P. de. Baixo Rendimento escolar: uma visão do professor. In: FUNAYAMA, C. A. (Org.) Problemas de aprendizagem: enfoque multidisciplinar. Campinas: Alínea, 2000. p.115-146.

GUILHERME, C. C. F. A Progressão Continuada e a inteligência do professor. In: REUNIÃO ANUAL DA ASSOCIAÇÃO NACIONAL DE PÓS-GRADUAÇÃO E PESQUISA EM EDUCAÇÃO, 26., 2003, Poços de Caldas. Anais... Poços de Caldas: ANPED, 2003. 1 CD ROM.

HABIGZANG, L. F. et al. A violência no contexto escolar e a inserção ecológica do psicólogo: um relato de experiência. In: KOLLER, S. H. (Org.) Ecologia do 
desenvolvimento humano: pesquisa e intervenção no Brasil. São Paulo: Casa do Psicólogo, 2005. p 355-379.

LISBOA, C.; KOLLER, S. H. O microssistema escolar e os processos proximais: exemplos de investigação científica e intervenções práticas. In: KOLLER, S. Ecologia do

desenvolvimento humano: pesquisa e intervenção no Brasil. São Paulo: Casa do Psicólogo, 2005. p 337-353.

MAGALHÃES, C. R. Escola e famílias: mundos que se falam? Um estudo no contexto de implementação da Progressão Continuada. 2004. 437 f. Tese (Doutorado em Educação) Universidade Federal de São Carlos, São Carlos, 2004.

NARVAZ, M. G, KOLLER, S. H. O modelo bioecológico do desenvolvimento humano. In: KOLLER, S. H. Ecologia do desenvolvimento humano: pesquisa e intervenção no Brasil. São Paulo: Casa do Psicólogo, 2005. p.51-65.

PATTO, M. H. de S. A família pobre e a escola pública: anotações sobre um desencontro. Psicologia USP, São Paulo, v.3, n. 1-2, p.107-121, 1992.

RAVAGNANI, M. C. A. N. Fracasso escolar: o discurso dos professores de ciências no contexto das propostas da nova LDB. 2001. 160 f. Dissertação (Mestrado em Educação Escolar) - Faculdade de Ciências e Letras, Universidade Estadual Paulista, Araraquara, 2001.

SÃO PAULO (Estado). Deliberação CEE n.9/97. Institui, no sistema de ensino no Estado de São Paulo, o regime de progressão continuada no ensino fundamental. São Paulo, 1997a. Disponível em: < http://www.crmariocovas.sp.gov.br/pdf/diretrizes_p0820-0830_c.pdf>. Acesso em: 19 nov. 2007.

SÃO PAULO (Estado). Secretaria de Estado de Educação. Indicação CEE No 8/97 - CP aprovada em 30.7.97. Relatores: Francisco Aparecido Cordão e Nacim Walter Chieco. São Paulo, 1997b. Disponível em:

<http://www.crmariocovas.sp.gov.br/pdf/ccs/Diretor2006/DiretorE_indicacao08_97_delibera cao09_97.pdf >. Acesso em: 19 nov. 2007.

SILVA, J. M. B. Progressão continuada por ciclos, trabalho docente e qualidade do ensino: um estudo de caso em escola de ensino fundamental do interior paulista. 2001. 195f. Dissertação (Mestrado em Educação Escolar) - Faculdade de Ciências e Letras, Universidade Estadual Paulista, Araraquara, 2001. 